\title{
The Optimal Capital Structure of an Economy
}

\author{
Hans Gersbach*
}

First version: December 1999

This version: March 2002

\begin{abstract}
In a general equilibrium model we examine the optimal allocation of equity and debt across banks and industrial firms when both are plagued by incentive problems and firms can borrow from banks. Increasing bank equity mitigates bank-level moral hazard but may exacerbate firm-level moral hazard due to dilution of firm equity. Competition of banks will not result in a socially efficient level of equity. Imposing capital requirements on banks can trigger the socially optimal capital structure of an economy in the sense of maximizing aggregate output. Such capital regulation is second-best and must balance three costs: excessive risk taking of banks, credit restrictions banks impose on firms with low equity, and credit restrictions because of high loan interest rates.
\end{abstract}

Keywords: financial intermediation, double incentive problems, bank capital, banking regulation, capital structure of the economy

JEL Classification: D41, E4, G2

*Alfred-Weber-Institut, University of Heidelberg, Grabengasse 14, 69117 Heidelberg, Germany. I would like to thank Charles Goodhart, Volker Hahn, Martin Hellwig, Bernhard Pachl, Eva Terberger seminar participants in Bielefeld and Heidelberg and conference participants at the annual meeting of the European Economic Association in Lausanne 2001 for valuable comments and suggestions. 


\section{Introduction}

Why should we be worried about the level of bank capital? Why is regulatory intervention needed to ensure an optimal level of bank capital? These questions have occupied economists, regulators, and bank managers over the past decades.

In this paper we provide a general equilibrium or macroeconomic perspective on the issues raised above. We highlight the costs and benefits of bank capital. Benefits arise when equity acts as a buffer against losses in the presence of macroeconomic risks or reduces excessive risk-taking by banks. The costs arise because banks compete with for industrial firms for equity. Higher bank capital can reduce the amount of equity supplied to industrial firms, thereby increasing moral hazard problems and credit constraints within the industrial firms that the banks are actually supposed to be easing. This lowers aggregate income since credit-constrained industrial firms have higher marginal products than investment in frictionless production. The socially optimal capital structure of an economy, or to put it differently, the optimal debt/equity ratios for financial intermediaries and for industrial firms, balance the costs and benefits of bank capital and will therefore maximize aggregate output. The considerations in the paper also indicate that the cost of bank capital corresponds to the marginal returns on equity of credit-constrained firms in an economy.

We also show that without regulatory intervention, banks will not and can not raise a socially efficient level of equity. An equilibrium with socially desirable equity levels cannot exist since banks cannot both refrain from risk taking and offer sufficiently high equity returns. Since banks compete with other firms for scarce equity, they need to offer sufficiently high returns to equity holders. If they attracted a sufficient amount of equity, banks would have no incentive to gamble. However, this would create insufficient returns compared to equity channeled into credit-constrained firms. As a result, bank equity will be lower than socially optimal equity levels, which induces banks to gamble and enables them to offer sufficiently high equity returns to attract equity in the market.

Regulatory capital requirements can eliminate gambling incentives for banks and can induce the socially preferable capital structure. Nevertheless, capital requirements cannot achieve a first-best allocation. Since under regulatory capital requirements, banks are forced to hold a certain amount of equity, they need to increase loan interest rates in order to generate returns that can attract equity to the extent required. Thus, capital requirements generate market power. Higher loan interest 
rates, however, reduce loan sizes for highly productive but credit-constrained firms which in turn lowers aggregate output. Therefore, capital adequacy rates must carefully balance three costs: gambling by banks, credit constraints on firms with low equity and credit constraints from high loan interest rates. In our model, the second-best capital requirement rule in the sense of maximizing aggregate output prescribes an equity level that minimizes the remaining costs as long as gambling by banks is avoided.

The general observations our model is consistent with are (i) banks face substantial costs of issuing equity (Calomiris and Wilson (1998)), (ii) banks absorb a large portion of equity in an economy (Gorton and Winton (2000)), (iii) without capital requirements banks are reluctant to raise additional capital freely (Blum and Hellwig (1995), Gorton and Winton (2000)) and (iv) bank loans and equity are the main source of funding of start-up firms (Petersen and Rajan (1994, 1995)) as we assume in this paper. While it is clear that our investigation can only be a first step towards a complete understanding of the optimal capital structure for an economy the tradeoffs introduced in this paper appear to be significant.

While our model tackles incentive problems at both bank and firm level from a macroeconomic perspective, there is a huge amount of literature on bank capital focusing on the incentive problem for banks alone. At the macroeconomic level, Blum and Hellwig (1995) have pointed out that strict capital adequacy rules may reinforce macroeconomic fluctuations. None of the existing work in the literature, however, addresses the optimal capital structure for an economy in the presence of multiple incentive problems, as this paper sets out to do.

A recent paper by Covitz and Heitfield (2000) examines the overlapping moral hazard problems between borrowers and banks, and between banks and a government guarantor in a partial setting with a focus on different issues. They establish that the relationship between market power and loan interest rates or bank risk hinges on the relative strength of the underlying moral hazard problems. In our paper we focus on the allocation of equity and debt across banks and firms in a macroeconomic

\footnotetext{
1 For instance, we leave out the co-existence of bank lending and bond financing developed by Besanko and Kanatas (1993), Hoshi, Kashyap, and Scharfstein (1993), Chemmanur and Fulghieri (1994), Boot and Thakor (1997), Holmström and Tirole (1997), and Repullo and Suarez (2000) and recently extended by Bolton and Freixas (2000) through introducing outside finance. In particular, these models with the model in this paper would further enhance our understanding of an optimal capital structure for an economy.

2 Rigorous summaries and discussions of banking regulation can be found in Dewatripont and Tirole (1994), and Freixas and Rochet (1997), and Bhattacharya, Boot and Thakor (1998).
} 
setting to mitigate multiple incentive problems in an economy.

We introduce an optimal capital structure for the economy and endogenize the cost of bank capital which is equal to the return on equity in credit constrained firms. Two recent papers have provided alternative perspectives on bank capital. First, Gorton and Winton (2000) have provided an interesting endogenization of the cost of bank capital. In their model, higher bank capital reduces the aggregate amount of bank deposits forcing consumers to hold more information-sensitive bank equity which, however, is a poor liquidity hedge. Since our approach is complementary to Gorton and Winton, one might expect to find that actual costs of bank capital are even higher than both papers suggest. Second, Diamond and Rajan (2000) have developed another plausible theory of bank capital where greater bank capital reduces liquidity creation by the bank but enables the bank to survive more often and to avoid distress. Again our work is complementary to Diamond and Rajan with respect to cost and benefits of bank capital.

The paper is organized as follows. In the next section we introduce the model. In the third section, we characterize the first-best allocations. We examine financial intermediation without regulatory intervention in the fourth section. In section five, we examine regulatory intervention and the socially optimal capital structure. Section six presents our conclusions.

\section{Model}

We consider a simple two-period model with one physical good that can be used either for consumption or investment. Time is indexed by $t(t=1,2)$. Agents live for both periods. The economy consists of a continuum of agents indexed by $[0,1]$. There are two classes of agents. A fraction $\eta$ of individuals consists of potential entrepreneurs. The rest $1-\eta$ of the population are consumers. The parameter $\eta$ captures the relation between supply of deposits and equity and will allow for comparative statics.

Potential entrepreneurs and consumers differ in that only the former have access to investment technologies. Moreover, a number of banks exist that gather equity capital from entrepreneurs and deposits from consumers in $t=1$. They invest the

3 In our context, regulatory capital requirements generate market power since banks must offer competitive equity returns. 
funds they have obtained in a portfolio of production technologies (described below) and pay back their claim-holders in $t=2$. Furthermore, each individual is endowed with one unit of labor when young and none when old.

\subsection{Technologies}

The economy has four production technologies. First, there exists a short-term constant-return technology that converts one unit of labor into $e>0$ units of the physical good in period $t=1$. Thus, each individual will obtain an endowment $e$ of goods when he supplies labor inelastically which is assumed. In the following we work directly with the endowments $e$ each individual obtains in the first period.

Second, each entrepreneur has access to a production project that converts timet goods into time-2 goods. The required funds for an investment project are at least $M>$ e. $M$ is the minimal amount of capital needed to obtain output. Hence, an entrepreneur must borrow at least $M-e$ units of the good in order to undertake the investment project. If an entrepreneur obtains additional resources and is able to invest an amount $I \geq M$, he realizes investment returns in the next period amounting to $q_{M} I\left(q_{M}>1\right) . q_{M}$ is the indicator of the productivity of investment projects. This technology is called the moral hazard technology since we assume that outsiders cannot verify whether an entrepreneur invests or not. Potential financiers thus face a standard moral hazard problem since entrepreneurs may want to consume the resources granted to them rather than invest. The non-verifiability of the investment decision is a standard scenario. Often, projects require specific human capital or may need the design of blueprints for machinery, buildings or logistics. Furthermore, an inventor may spend a lot of time on reading and designing. Whether the efforts are directed towards the project or whether blueprints are competently drafted is unlikely to be observed by outsiders. Even if it becomes clear for financiers ex post whether the entrepreneur has invested or not, investment decisions are not verifiable in court.

Third, there is a gambling technology $(\mathbf{G T})$ in which banks can invest ${ }^{4}$ and which also converts time- 1 goods into time- 2 goods. If an amount of $G$ is invested in this technology, the output is given by $q_{G} z G$ where $q_{G}>1$ and $z$ is uniformly distributed over $[0,1]$. The possibility of gambling will introduce moral hazard problems for fi-

4 In addition, we might assume that entrepreneurs can use the gambling technology as well, which will tend to increase the cost of bank capital. 
nancial intermediaries. Gambling technologies may represent investments in particular risky sectors in an economy or, in an international context, may be investments in emerging markets.

Fourth, there is a standard constant return technology that converts time goods into time- $t+1$ goods. The gross return per unit of investment is given by $q_{F}>1$. We call this technology frictionless production $(\mathbf{F T})$.

The assumptions about the different long-term production technologies are as follows:

\section{Assumption 1}

$q_{G}>q_{M}>q_{F}>q_{G} / 2$

Thus gambling promises the highest return on investment if the shock turns out to be favorable. The moral hazard technology itself is better than the frictionless technology, which in turn dominates the expected return of the gambling technology. It is obvious from our assumption (1) that the gambling technology should never be used in a first-best world since the moral hazard technology or the frictionless technology can absorb an unlimited amount of resources and yield higher expected returns. The constant return assumption across technologies is solely made for tractability. ${ }^{5}$

\section{$2.2 \quad$ Agents}

For simplicity, we assume that potential entrepreneurs are risk-neutral and only care about consumption when they are old, i.e. they do not consume when young. Consumers consume in both periods. They have utility functions $u\left(c^{1}, c^{2}\right)$ defined over consumption in the two periods, where $c^{1}$ and $c^{2}\left(c^{1} \geq 0, c^{2} \geq 0\right)$ are the consumption of the consumer when young and old, respectively. For simplicity of exposition, we assume that consumers are extremely risk-averse and therefore only the lowest possible consumption in the second period enters utility. That is, the utility of consumers can be written as $u\left(c^{1}, \min \left\{c^{2}\right\}\right)$ when there is uncertainty about the second-period consumption level. There is never uncertainty about consumption in the first period. Additionally consumers want to smooth consumption over their

5 Interesting extensions concern decreasing returns of the moral hazard and frictionless technology such that in a first-best world all technologies are used and which would allow the formalization of the notion of a credit crunch when bank lending rates rise as a consequence of higher capital requirements. 
lifetime. If a consumer can transfer wealth with certainty between the two periods at a real interest rate, denoted by $r(r>1)$, the solution of the household problem generates the saving function, denoted by $S(r)(S(r) \geq 0)$. We follow the standard assumptions in the OLG literature that the substitution effect (weakly) dominates the income effect, i.e. savings are a weakly increasing function of the interest rate. As our conclusions only rely on the assumption that savings of consumers are channeled to banks, there are a variety of alternative formulations which lead to the same results. For instance, the easiest way is to assume that consumers only consume in the second period as well and thus all endowments are available for lending to banks. This would avoid the endogeneity of consumers' saving decisions. However, the interest rate feedback might be important and therefore we work with the more complicated version.

\subsection{Financial Intermediation}

To alleviate the moral hazard problem on the side of entrepreneurs, financial intermediators can act as delegated monitors in Diamond's (1984) sense of the term. This monitoring function can justify their existence. Moreover, if $M-e>e$, intermediaries can be motivated by the fact that more than one investor is required to fund a project.

We work with the former motivation for financial intermediaries and assume that there are $n$ banks, indexed by $i$, that can finance entrepreneurs. For all of our arguments, it will be sufficient for two banks to exist and compete.

As delegated monitors, banks are assumed to have access to a monitoring technology. If they have granted a loan with face value $l(l \geq 0)$ to an entrepreneur who does not invest, this technology secures a repayment of $\beta l(0 \leq \beta \leq 1)$ when they pay a resource cost. If banks do not monitor, we assume that the repayment from noninvesting entrepreneurs will be zero since entrepreneurs simply consume the funds. Monitoring can take many forms. For instance, banks can collateralize parts of the credit or may release the funds sequentially to the entrepreneur, depending on his investment behavior. Such efforts can reduce the private benefits of entrepreneurs who do not invest. Hence, a non-investing entrepreneur with a loan of face valuel only obtains $(1-\beta) l$ if the bank monitors and he does not invest. We assume that monitoring costs are sufficiently small, such that banks will always decide to monitor when they grant loans. For simplicity of exposition, we will neglect the monitoring 
outlays in the following examinations. Moreover, our results do not depend on whether $\beta$ is positive. Even if banks merely collect funds from many consumers to fund few entrepreneurs, the results apply by setting $\beta=0$. Finally, we assume that entrepreneurs can only obtain a loan from one bank ${ }^{6}$ and that entrepreneurs, when indifferent between investing and consuming funds will choose to invest.

When an entrepreneur has invested, the monitoring problem is different. We assume that the verification of output conditional on investment is possible. The assumption is most easily justified if the final products of an entrepreneur's project are physical goods such as houses or machines, so that lenders can secure repayment conditional on investment at very low cost.

Next, we discuss the set of strategic variables that a bank can set in $t=1$. In order to fund investments, the bank offers deposit contracts to consumers at deposit rates denoted by $d_{i}\left(d_{i} \geq 0\right)$. We assume that consumers only invest in deposits. A standard justification is the extreme risk aversion of consumers as we do in this paper. ${ }^{7}$ Banks then receive deposits measuring $D_{i}(i=1, \ldots, n)\left(D_{i} \geq 0\right)$. Thus, they promise depositors a repayment $d_{i} D_{i}$. The second source of funding is equity contracts offered by potential entrepreneurs. Under such contracts, the holder will obtain the right to participate in the dividend payments in the next period according to his share in overall equity issued by the bank. We use $E_{i}\left(E_{i} \geq 0\right)$ to denote the amount of equity capital that bank $i$ receives in $t=1$. Equity holders are the owners and thus residual claimants of banks and will therefore wish to maximize the return on equity. In practice, this task is delegated to managers, for whom we assume correspondingly that they act in the interest of shareholders.

Finally, we describe the investment opportunities of banks.

First, they can offer loan contracts $\left(l_{i}, R_{i}^{l}\right)$ to entrepreneurs where $l_{i}\left(l_{i} \geq 0\right)$ denotes the size of the loan made to a single entrepreneur and $R_{i}^{l}\left(R_{i}^{l} \geq 1\right)$ the required return. ${ }^{8}$ Denote the fraction of entrepreneurs that applies for a loan of bank $i$ by $\lambda_{i}$ $\left(0 \leq \lambda_{i} \leq 1\right)$. Hence the bank grants loans of an overall size of $L_{i}=\lambda_{i} \eta l_{i}$.

Second, the bank can invest an amount of $F_{i}$ in FT and an amount of $G_{i}$ in GT.

6 Implicitly, we assume that the monitoring activities of banks include checking whether an entrepreneur applies for loans at other banks.

7 However, with appropriate capital regulation equity contracts are not risky anymore and in such circumstances consumers might want to hold equity as well. Adding arbitrarily small idiosyncratic risk would, however, again induce consumers to invest only in deposits in this case as well.

8 Note that since entrepreneurs are identical, we can w.l.o.g. assume that loan sizes and the required rates of return do not differ for individual entrepreneurs. 
Thus the overall budget restriction of each bank in $t=1$ is given by

$$
E_{i}+D_{i}=L_{i}+F_{i}+G_{i} \quad(i=1, \ldots, n) .
$$

To complete our description of the model we assume

\section{Assumption 2}

$(1-\eta) S\left(q_{F}\right)>\eta(M-e)$

Assumption 2 simply indicates that funds from entrepreneurs and consumers suffice to provide capital for all projects of the moral hazard technology to operate at minimal scale when consumers earn the return rate $q_{F}$. If assumption 2 is violated, only a subset of entrepreneurs can be funded, which complicates the analysis without providing further insights.

\section{First-Best Allocation}

We first examine the first-best allocation when no frictions are present. We assume that there exists a perfect capital market in which consumers can directly offer their savings to the different types of technologies and particularly to entrepreneurs who, in turn, can contract upon their investment decisions and can credibly promise repayments. We obtain:

\section{Proposition 1}

If assumption 1 and 2 hold, the first-best allocation is characterized by

(i) No resources flowing into the gambling or into the frictionless technology.

(ii) One (risk-less) equilibrium return on savings given by $\bar{R}^{F B}=q_{M}$.

(iii) All consumers saving $S\left(q_{M}\right)$ and each entrepreneur investing an amount of

$$
e+\frac{1-\eta}{\eta} S\left(q_{M}\right)
$$

(iv) An aggregate second-period output $Y^{F B}$ given by

$$
Y^{F B}=q_{M}\left[\eta e+(1-\eta) S\left(q_{M}\right)\right]
$$

Proposition 1 follows immediately from the description of the model. Returns on savings must be equal to the marginal returns of capital $q_{M}$. At such returns on 
savings, consumers offer $S\left(q_{M}\right)$ in the terms of savings, whereas entrepreneurs use their own funds and their borrowings to run their projects. An important characteristic of the first-best allocation is that neither the frictionless technology nor the gambling technology are funded in equilibrium, simply because the moral hazard technology dominates the other production possibilities in terms of marginal and average returns. Note that in a first-best world, the capital structure is irrelevant because there is no difference between equity and debt contracts since there is no risk for investors.

\section{Intermediation}

In this section we examine an economy with the frictions described in section 2 . We first describe the complete sequence of events in the intermediation game.

\section{Period 1}

1. Banks offer equity contracts and entrepreneurs decide how much to invest in bank equity

2. Banks offer loan contracts $\left(l_{i}, R_{i}^{l}\right)$ to a fraction of entrepreneurs.

3. Banks offer deposit contracts $\left(d_{i}\right)$ to consumers.

4. Consumers and entrepreneurs decide which contracts to accept. Resources are exchanged. Bank $i$ receives a measure $D_{i}$ of deposits and receives a measure $E_{i}$ of equity capital.

5. Entrepreneurs decide which to accept and each bank grants the loans to each entrepreneur who has accepted. The overall size of loans granted by bank $i$ is denoted by $L_{i}$.

6. Banks decide how much they want to invest in the gambling and frictionless technologies $G_{i}$ and $F_{i}$.

\section{Period 2}

6. Entrepreneurs pay off the loans. Returns from the gambling and frictionless technology are realized. Banks pay back depositors. The remaining dividends are distributed among shareholders. 
Note that banks cannot credibly commit to their investment decisions when they offer contracts. Therefore, deposits may be risky, depending on the amount of investment into gambling. To solve for the overall equilibrium, we will proceed in steps, as this helps to simplify the exposition of the arguments and reduces the complexity. In each step some of the variables are kept constant. At the end of the exercise, we will discuss our findings and show that the overall solution is indeed a subgame-perfect equilibrium of the whole game. In all considerations it is assumed that entrepreneurs and consumers follow symmetric strategies, e.g. all entrepreneurs obtain the same loan contracts and offer the same equity contracts. Moreover, w.l.o.g. we only investigate symmetric equilibria with respect to banks' strategy choices and we will omit the index for banks whenever there is no resulting confusion.

Note that the sequence of events implies that banks offer loan contracts before deposit contracts. On the one hand this simplifies the examination of possible deviations from the equilibria, on the other hand it is important for the existence of equilibria. The equally plausible sequence in which deposit contracts are offered first generates the same equilibria only under certain parameter constellations, since banks have the possibility of offering higher deposit rates and cornering the deposit market in order to exploit monopoly power in the loan market.

\subsection{Loan Contracts}

We first discuss the contracting problem between banks and entrepreneurs after entrepreneurs have given the banks equity of $e^{+}:=\sum_{i=1}^{n} e_{i}$ and the banks have received deposits. Hence, the remaining equity resources of an entrepreneur for his own investment projects are given by $e^{-}:=e-e^{+}$. For the examination of loan contracts, we assume that banks have a centralized information system that guarantees that the entrepreneur can only have one loan contract. Given a loan contract $\left(l_{i}, R_{i}^{l}\right)$ offered by a bank, the entrepreneur can either invest and obtains

$$
q_{M} e^{-}+\left(q_{M}-R_{i}^{l}\right) l_{i}
$$

9 Our analysis also holds mutatis mutandis, if the entrepreneur can obtain loan offers from all banks. In this case each bank will only offer $1 / n$ of the credit volume that still motivates the entrepreneur to invest. Note also that banks anticipate that $R^{e} \geq q_{M}$ would lead entrepreneurs to consume all borrowed sums and not invest at all. Hence, banks would never offer $R^{e} \geq q_{M}$. 
or he can simply consume his funds and obtains

$$
e^{-}+(1-\beta) l_{i}
$$

since the bank can recover $\beta l_{i}$ as the collateral. Hence, entrepreneurs will decide to invest if and only if

$$
l_{i} \leq l^{*}\left(R^{l}, e^{-}\right):=\frac{e^{-}\left(q_{M}-1\right)}{(1-\beta)-\left(q_{M}-R^{l}\right)} .
$$

Note that $l^{*}\left(R^{e}, e^{-}\right)$is monotonically decreasing in $R^{l}$. A higher loan rate requires a smaller loan size in order for entrepreneurs to still invest. As we will see capital requirements raise $R^{e}$ and thus impose tighter credit restrictions on entrepreneurs. To proceed, we introduce the following assumption, which we assume to hold throughout the paper:

\section{Assumption 3}

$1-\beta>q_{M}-q_{F}$

Assumption 3 guarantees that banks will offer loan contracts in equilibrium. Note that according to assumption 3 the constraint (1) is binding for all loan rates $R_{i}^{l} \geq q_{F}$ since $1-\beta-\left(q_{M}-R^{l}\right)>0$. Assumption 3 also implies that for fixed $e^{-}$, the functions $l^{*}\left(R^{l}, e^{-}\right)$as well as $R^{l} l^{*}\left(R^{l}, e^{-}\right)$are monotonically decreasing in $R^{l}$. In the following for ease of presentation, we assume a tie-breaking rule: If banks are indifferent between offering loans and investments in the frictionless technology they choose the former. We obtain:

\section{Proposition 2}

Suppose that, in an equilibrium, banks offer loan contracts and invest a positive amount in the frictionless technology and that entrepreneurs' inside capital is given by $e^{-}$. We define $l^{*}\left(e^{-}\right):=l^{*}\left(q_{F}, e^{-}\right)$and obtain:

(i) If $e^{-}+l^{*}\left(e^{-}\right)<M$, then no loans are granted.

(ii) If $e^{-}+l^{*}\left(e^{-}\right) \geq M$, then there exists a unique equilibrium $R_{i}^{l}=q_{F}$ and $l_{i}=l^{*}\left(e^{-}\right)(i=1, . ., n)$.

The proof is given in the appendix. In proposition 2 two cases can occur. In the first case, the maximal loan size that can guarantee a repayment $q_{F}$, together with entrepreneur's equity cannot cover the minimal project size. In the second case inside 
equity and the maximal loan at rate $q_{F}$ such that entrepreneur invest can cover $M$. Hence, banks offer exactly $l^{*}\left(e^{-}\right)$and expect a sure repayment. Proposition 2 implies that banks offer loan contracts at rate $q_{F}$ as long as the equity of entrepreneurs is sufficient to motivate them to invest and to pay back. Then equilibrium interest rates on loans are equal to the refinancing costs and thus intermediation margins are zero.

\subsection{Gambling and Frictionless Investments}

We next discuss the remaining investment decisions of banks. They are derived under the assumption that banks only grant loans if they (correctly) anticipate that entrepreneurs will invest and honor their repayment promises. Positive profits for the bank then occur only if

$$
\Pi=q_{G} z G+q_{F}(E+D-G-L)+R^{l} L-d D \geq 0
$$

or, equivalently if

$$
z \geq \frac{1}{q_{G}}\left(q_{F}-\frac{H}{G}\right):=\underline{z}(G)
$$

where

$$
H:=q_{F}(E+D-L)+R^{l} L-d D .
$$

Note that we assume that banks maximize expected returns on equity and thus profits are the dividends shareholders receive. Because of limited liability only positive realizations need to be taken into account. Because at the investment stage $E$ is given and we can therefore directly work with the absolute amount of dividends accruing to shareholders. We need to distinguish the following two cases: First, $\underline{z}(G) \leq 0$. In this case, expected profits are given by

$$
\pi^{(1)}(G)=\int_{0}^{1} \Pi d z=\left(\frac{1}{2} q_{G}-q_{F}\right) G+H
$$

whereas they amount to

$$
\pi^{(2)}(G)=\int_{\underline{z}(G)}^{1} \Pi d z=\frac{1}{2} q_{G} G\left(1-(\underline{z}(G))^{2}\right)+(1-\underline{z}(G))\left(H-q_{F} G\right)
$$

in the other case. In order to derive the optimal investment $G$ in the gambling technology we observe that $\pi^{(1)}(G)$ monotonically decreases in $G$ because $\frac{1}{2} q_{G}<q_{F}$. Therefore in the case of $\pi^{(1)}(G)$ the optimal choice is $G=0$. In the case of $\pi^{(2)}(G)$, 
we take the derivatives of the profit function using equation (2), equation (3) and equation (4):

$$
\begin{aligned}
\frac{d \pi^{(2)}(G)}{d G} & =\frac{d}{d G}\left(\frac{1}{2} q_{G} G\left(1-\frac{1}{q_{G}^{2}}\left(q_{F}-\frac{H}{G}\right)^{2}\right)+\left(1-\frac{1}{q_{G}}\left(q_{F}-\frac{H}{G}\right)\right)\left(H-q_{F} G\right)\right) \\
& =\frac{d}{d G}\left(\frac{1}{2} q_{G} G+H-q_{F} G+\frac{G}{2 q_{G}}\left(q_{F}-\frac{H}{G}\right)^{2}\right) \\
& =\frac{1}{2} q_{G}-q_{F}+\frac{1}{2 q_{G}}\left(q_{F}-\frac{H}{G}\right)^{2}+\frac{1}{q_{G}}\left(q_{F}-\frac{H}{G}\right) \frac{H}{G} \\
& =\frac{1}{2} q_{G}-q_{F}+\frac{q_{F}^{2}}{2 q_{G}}-\frac{q_{F}}{q_{G}} \frac{H}{G}+\frac{1}{2 q_{G}} \frac{H^{2}}{G^{2}}+\frac{q_{F}}{q_{G}} \frac{H}{G}-\frac{1}{q_{G}} \frac{H^{2}}{G^{2}} \\
& =\frac{1}{2 q_{G} G^{2}}\left(\left(q_{G}-q_{F}\right)^{2} G^{2}-H^{2}\right)
\end{aligned}
$$

Since

$$
\frac{d^{2} \pi^{(2)}(G)}{d G^{2}}=\frac{H^{2}}{q_{G} G^{3}}
$$

is negative only for negative $G$, the maximum of $\pi^{(2)}(G)$ is given by choosing $G=$ $E+D-L$ (complete gambling) or $G=0$ (no gambling). To proceed, we introduce the following assumption, which we assume to hold throughout the paper:

\section{Assumption 4}

$\frac{1-\eta}{\eta} \frac{S\left(q_{F}\right)}{e}>\frac{q_{M}-1}{1-\beta-\left(q_{M}-q_{F}\right)}$

Assumption 4 implies that loans $L$ are smaller than deposits $D$ for any two possible interest rates $d$ and $R^{l}$. Since $R^{l} \geq d$, in any potential equilibrium, it follows that $R^{l} L-d D<0$. This implies that $\left.\underline{z}(G)\right|_{G=E+D-L}>0$ in the gambling case. In the non-gambling case we have $\lim _{G \rightarrow 0} \underline{z}(G)=-\infty$. Then profits in the non-gambling and in the gambling case are given by:

$$
\begin{aligned}
\pi_{F}= & \left.\pi^{(1)}(G)\right|_{G=0} \\
= & H \\
= & q_{F}(E+D-L)+R^{l} L-d D \\
\pi_{G}= & \left.\pi^{(2)}(G)\right|_{G=E+D-L} \\
= & \frac{1}{2} q_{G}(E+D-L)\left(1-\left(\frac{R^{l} L-d D}{q_{G}(E+D-L)}\right)^{2}\right) \\
& \quad+\left(1-\frac{R^{l} L-d D}{q_{G}(E+D-L)}\right)\left(R^{l} L-d D\right) \\
= & \frac{1}{2} q_{G}(E+D-L)\left(1+\frac{R^{l} L-d D}{q_{G}(E+D-L)}\right)^{2}
\end{aligned}
$$


We summarize these observations in the following proposition:

\section{Proposition 3}

Suppose that assumptions 1 to 4 hold and a bank has received depositsD at deposit rate $d$, equity $E$ and has granted loans $L$ at loan interest rate $R^{l}$. Then the bank

(i) does not gamble: $G=0$ if $\pi_{F} \geq \pi_{G}$, i.e.

$$
q_{F} \geq \frac{1}{2} q_{G}\left(1+\left(\frac{R^{l} L-d D}{q_{G}(E+D-L)}\right)^{2}\right)
$$

(ii) gambles completely: $G=E+D-L$ if $\pi_{F}<\pi_{G}$, i.e.

$$
q_{F}<\frac{1}{2} q_{G}\left(1+\left(\frac{R^{l} L-d D}{q_{G}(E+D-L)}\right)^{2}\right)
$$

By solving (7) for $E$ and recalling that due to assumption $4, R^{l} L-d D<0$ holds, we obtain the following corollary:

\section{Corollary 1}

There exists a unique value of $E, E^{*}$, such that banks gamble completely if and only if

$$
E \leq E^{*}:=\frac{-\left(R^{l} L-d D\right)}{\sqrt{q_{G}\left(2 q_{F}-q_{G}\right)}}-(D-L)
$$

Corollary 1 implies that banks gamble if the level of equity is small and below a critical level. For $q_{G}\left(2 q_{F}-q_{G}\right) \leq 1$, the critical equity level is ceteris paribus increasing in $D$ and decreasing in $L$. A larger amount of deposits for a given level of $E$ increases incentives to gamble, which requires a larger threshold for $E$ to stop gambling. The more funds are invested in loans, the smaller is the incentive to gamble. In order to derive the overall equilibrium, we proceed sequentially. In the first step, we assume that banks offer deposit contracts where $d_{i}=q_{F}$. Whether or not $d_{i}=q_{F}$ holds in equilibrium depends on the following two considerations. If banks gamble, expected returns for depositors may be smaller than $q_{F}$ and thus the announcement $d_{i}=q_{F}$ may not be credible. If banks prefer not to gamble, we have to check whether banks might not credibly offer higher interest rates than $q_{F}$. We will return to these issues when we establish the overall equilibrium. 


\subsection{Deposit and Equity Contracts}

Next we derive the amount of equity that banks will obtain in equilibrium. We first calculate marginal returns on equity. We use $R^{e b}(E)$ to denote the marginal return on equity invested in a bank. Similarly, we use $R^{e f}\left(e^{-}\right)$to denote the marginal return on equity invested in the entrepreneur's project. Let us first calculate $R^{e f}\left(e^{-}\right)$. The payoff for entrepreneurs from investing in the project in equilibrium is denoted by $g$ and given by

$$
g=q_{M}\left(e^{-}+l^{*}\left(R^{e}, e^{-}\right)\right)-l^{*}\left(R^{e}, e^{-}\right) R^{l}
$$

If an entrepreneur increases the amount of equity devoted to his project, he could obtain a larger loan. Inserting (9) into (1) and differentiating yields the equilibrium returns on equity in firms $R^{e f}$ :

$$
\begin{aligned}
R^{e f}\left(e^{-}\right) & =\frac{\partial g}{\partial e^{-}} \\
& =\frac{\partial}{\partial e^{-}}\left(q_{M}\left(e^{-}+l^{*}\left(R^{e}, e^{-}\right)\right)-l^{*}\left(R^{e}, e^{-}\right) R^{l}\right) \\
& =\frac{\partial}{\partial e^{-}}\left(q_{M}\left(e^{-}+\frac{e^{-}\left(q_{M}-1\right)}{(1-\beta)-\left(q_{M}-R^{l}\right)}\right)-\frac{e^{-}\left(q_{M}-1\right)}{(1-\beta)-\left(q_{M}-R^{l}\right)} R^{l}\right) \\
& =q_{M}+\frac{q_{M}-1}{(1-\beta)-\left(q_{M}-R^{l}\right)}\left(q_{M}-R^{l}\right) \\
& =\frac{R^{l}-\beta q_{M}}{1-\beta-\left(q_{M}-R^{l}\right)}>q_{M}
\end{aligned}
$$

Therefore, return on equity is larger ${ }^{10}$ than $q_{M}$ since entrepreneurs can enlarge their debt capacity by keeping more equity for themselves. In equilibrium, the return on equity offered by banks must be at least equal to $R^{e f}$, otherwise entrepreneurs would not be willing to accept bank equity contracts. The payoff from investing in bank equity for entrepreneurs is given by:

$$
b_{k}=\frac{\pi_{k}}{E} e^{+}
$$

$k$ is an indicator variable which represents either the gambling or the non-gambling case $(k=G, F)$. $\frac{\pi^{k}}{E}$ does not depend on $e^{+}$since a single entrepreneur can only marginally change the total amount of equity a bank receives. In order to compare return on equity in firms and banks, we assume for the moment that $R^{l}=d=q_{F}$. Then, the return on bank equity is given as:

$\overline{10 \text { Note that for } R^{l} \geq q_{F} \text { and from } 1-\beta}>q_{M}-R^{l}$ it directly follows that $R^{l}>\beta q_{M}$. 
- non-gambling case:

$$
R^{e b}=\frac{\partial b_{F}}{\partial e^{+}}=q_{F}
$$

- gambling case:

$$
R^{e b}=\frac{\partial b_{G}}{\partial e^{+}}=\frac{\pi^{G}}{E}
$$

\section{Proposition 4}

Assume assumptions 1 to 4 hold. Then, a subgame-perfect equilibrium with $R^{l}=$ $d=q_{F}$ and no gambling does not exist.

Proof. Then $R^{e f}>q_{M}$ and $R^{e b}=q_{F}$ in the non-gambling case, which implies $E=0$. But since $E^{*}>0$, which follows from (8), and $D>L$ and $q_{G}>q_{F}, E<E^{*}$ holds, which by corollary 1 implies that the bank intends to gamble completely. Therefore, no equilibrium without gambling can exist.

The reasoning for proposition 4 runs as follows. If banks obtained a large equity portion, inducing them not to gamble, equilibrium returns on equity would be $q_{F}$, which is smaller than the returns on equity for firms. Therefore, this cannot be an equilibrium.

Proposition 4 has important implications. If banks attracted a sufficient amount of equity, they would have no incentive to gamble as this would yield a low return on equity. This, in turn, makes it impossible for banks to attract a high level of equity in the first place. Since banks cannot both refrain from gambling and offer sufficiently high equity returns at the same time, no subgame-perfect equilibrium with non-gambling can exist.

We next examine the gambling case. If $R^{e f}=R^{e b}$ in the gambling case, the entrepreneur will be indifferent between investing in his project or in equity contracts. Thus we can calculate for the level of equity at the bank.

From $R^{e f}=R^{e b}$ and thus $R^{e f} E=\pi^{G}$ we obtain for $R^{l}=d=q_{F}$ :

$$
E R^{e f}=\frac{1}{2} q_{G}(E+D-L)\left(1+\frac{q_{F}(L-D)}{q_{G}(E+D-L)}\right)^{2}
$$


After rearranging terms and adding $2 q_{G} R^{e f}(D-L)(E+D-L)$ on both sides, we get:

$$
\begin{aligned}
2 R^{e f} q_{G}(E+D-L)^{2} & =\left(q_{G}(E+D-L)-q_{F}(D-L)\right)^{2} \\
& +2 q_{G} R^{e f}(D-L)(E+D-L)
\end{aligned}
$$

Setting $X=E+D-L$ yields:

$$
X^{2} q_{G}\left(2 R^{e f}-q_{G}\right)-2 X q_{G}\left(R^{e f}-q_{F}\right)(D-L)-q_{F}^{2}(D-L)^{2}=0
$$

Since $R^{e f}>q_{F}>0$ and $D \geq L$ the quadratic equation has a positive solution only if $2 R^{e f}>q_{G}$. If $2 R^{e f}>q_{G}$ there exist two real solutions, one negative and one positive. The positive root yields the solution:

$$
\left.X=\frac{D-L}{2 R^{e f}-q_{G}}\left(R^{e f}-q_{F}+\sqrt{R^{e f}\left(R^{e f}-2 q_{F}\left(1-\frac{q_{F}}{q_{G}}\right)\right.}\right)\right)
$$

or

$$
E^{* G}=\frac{D-L}{2 R^{e f}-q_{G}}\left(q_{G}-q_{F}-R^{e f}+\sqrt{R^{e f}\left(R^{e f}-2 q_{F}\left(1-\frac{q_{F}}{q_{G}}\right)\right)}\right)
$$

We obtain:

\section{Proposition 5}

If assumptions 1 to 4 hold, then:

$$
E^{* G}>0
$$

The proof of proposition 5 is given in the appendix. Proposition 5 shows that the level of equity banks attract in the gambling case is indeed positive. Equation (14) shows how the level of bank equity $E^{* G}$ in the gambling case is related to the amount of deposit and loans and to return on firm equity $R^{e f}$, which itself depends on the loan interest rate $R^{l}$.

\subsection{Overall Equilibrium}

We are now ready to characterize the overall subgame-perfect equilibrium. Before we turn to the equilibrium we need to address the defaults of banks. We will proceed in two steps. In the first step and in the following proposition we assume that deposits 
are insured up to the maximal return $q_{F}$. If a bank fails, depositors will be protected by government transfers which are assumed to be raised by lump sum taxation in period 2. Therefore, deposits are safe and lump sum taxation in period 2 will have no distortionary effects on the behavior in period 1. In the second step we discuss what happens when there is no deposit insurance. We obtain

\section{Proposition 6}

If assumptions 1 to 4 hold and deposits are insured, then a subgame-perfect equilibrium exists:

$$
\begin{aligned}
R^{l} & =d=q_{F} \\
D & =\frac{1-\eta}{n} S\left(q_{F}\right) \\
E & \left.=E^{* G} \text { (as defined by equation }(14)\right) \\
L & =\frac{\eta}{n} l^{*}\left(q_{F}, e^{-}\right) \text {where } e^{-}=e-\frac{n}{\eta} E^{* G} \\
G & =E+D-L \\
F & =0
\end{aligned}
$$

Proof. Let us first consider the equilibrium choice $d=q_{F}$. A deviation $d_{i}<q_{F}$ would leave a bank without deposits. A deviation $d_{i}>q_{F}$ cannot credibly promise higher returns on deposits since returns on loans are $q_{F}$ and the expected returns on gambling are smaller than $q_{F}$. A deviation to higher loan rates, $R_{i}^{l}>q_{F}$, would not attract any entrepreneurs and therefore is also not profitable. From proposition 2 we must have $R^{l}=d$ and therefore $R^{l}=d=q_{F}$. Thus, $D$ is given by $\frac{1-\eta}{n} S\left(q_{F}\right)$. The fact that an equilibrium can only exist if the bank gambles completely follows from proposition 4 .

Proposition 6 indicates that under certain parameter restrictions an equilibrium with complete gambling, loan contracts and zero intermediation margins exists. It is obvious that the allocation is inefficient since gambling is undesirable. We will show that stipulating larger bank capital requirement can improve welfare although moral hazard problems at firms will be less mitigated.

If deposits are not insured proposition 6 needs to be adjusted in one important aspect. Since banks gamble and depositors are assumed to be extremely risk averse, the savings decisions of depositors have to be based on the lowest return the gambling investment yields, i.e. $z=0$. If we assume that the liquidation value is distributed evenly across depositors in case a bank defaults, saving decisions of depositors are based on the relationship between $R^{l} L$ and $D$. Therefore $S=S\left(\frac{R^{l} L}{D}\right)$ will enter 
into the equilibrium considerations. This additional endogeneity does lead to the same qualitative features of the equilibrium, but without a specific savings function $S$, the equilibrium cannot be solved anymore explicitly.

\section{Optimal Capital Structure}

In the previous section, we saw that although banks obtain equity, a general equilibrium implies gambling and inefficient allocation. In this section, we allow for regulation to force banks to adopt a particular capital structure. A key consideration is that banks can only fulfill capital requirements in the non-gambling case if they make profits. This means they must set $R^{l}$ higher than deposit rates in order to attract equity and to be allowed to operate. Thus, capital requirement will generate market power. And therefore a regulator must set the amount of equity $E$ for banks sufficiently high in order that banks are able to offer loan contracts with a return $R^{l} \in\left(q_{F}, q_{M}\right)^{11}$ such that $R^{e b}$ equals $R^{e f}$ in the non-gambling case. We use $E^{R}$ to denote the equity level imposed by regulatory requirements. The return equalization in the equity market yields

$$
\begin{aligned}
R^{e f} & =R^{e b} \\
\frac{R^{l}-\beta q_{M}}{1-\beta-q_{M}+R^{l}} & =\frac{q_{F}(E+D-L)+R^{l} L-d D}{E}
\end{aligned}
$$

where we have applied (10), $R^{e b}=\frac{\pi}{E}$, and $\pi=q_{F}(E+D-L)+R^{l} L-d D$. Using $d=q_{F}$ and $L=\frac{\eta}{n}\left(e-\frac{n}{\eta} E\right) \frac{q_{M}-1}{1-\beta-q_{M}+R^{l}}$ and solving for $E$ yields:

$$
E^{R}\left(R^{l}\right)=\left(\frac{e \eta}{n}\right)\left(\frac{q_{M}-1}{q_{M}-q_{F}}\right)\left(\frac{R^{l}-q_{F}}{R^{l}-\beta}\right)
$$

Note that $E^{R}\left(R^{l}\right)$ monotonically increases and concave for $R^{l} \in\left(q_{F}, q_{M}\right)$ with $E^{R}\left(q_{F}\right)=0$ and $E^{R}\left(q_{M}\right)=\left(\frac{e \eta}{n}\right)\left(\frac{q_{M}-1}{q_{M}-\beta}\right)$. On the other hand, equity $E$ for banks must exceed $E^{*}$ in order to induce them to refrain from gambling. To discuss $E^{*}=E\left(L\left(E, R^{l}\right), R^{l}\right)$ we need some further evaluations of $E^{*}$. Recall from equation (8) that $E^{*}$ is given by:

$$
E^{*}=\frac{-R^{l} L+d D}{\sqrt{q_{G}\left(2 q_{F}-q_{G}\right)}}-(D-L)
$$

11 Since the return on an entrepreneur's project is $q_{M}$, he would not accept loan contracts with $R^{l} \geq q_{M}$ 
Inserting $L=\frac{\eta}{n}\left(e-\frac{n}{\eta} E^{*}\right) \frac{q_{M}-1}{1-\beta-q_{M}+R^{l}}, d=q_{F}$ and using the abbreviations $r_{M}=$ $q_{M}-1$ and $\tilde{r}=\sqrt{q_{G}\left(2 q_{F}-q_{G}\right)}$, we obtain:

$$
E^{*}=\frac{-R^{l}\left(\frac{\eta}{n} e-E^{*}\right) \frac{r_{M}}{R^{l}-\beta-r_{M}}+q_{F} D}{\tilde{r}}-D+\left(\frac{\eta}{n} e-E^{*}\right) \frac{r_{M}}{R^{l}-\beta-r_{M}}
$$

Inserting $D=\frac{1-\eta}{n} S\left(q_{F}\right), E^{*}\left(R^{l}\right)$ is then given as:

$$
E^{*}\left(R^{l}\right)=\frac{1}{n} \frac{\left(q_{F}-\tilde{r}\right)(1-\eta) S\left(q_{F}\right)-\frac{r_{M}\left(R^{l}-\tilde{r}\right)}{R^{l}-r_{M}-\beta} \eta e}{\tilde{r}-\frac{r_{M}\left(R^{l}-\tilde{r}\right)}{R^{l}-r_{M}-\beta}}
$$

\subsection{Optimal Capital Structure with $\beta=0$}

We now compute the level of $R^{l}$ that equalizes $E^{*}\left(R^{l}\right)$ and $E^{R}\left(R^{l}\right)$. For simplicity, we assume $\beta=0$, i.e. the recovery rate to be zero. We will later generalize our results for $\beta \neq 0$. $E^{*}\left(R^{l}\right)=E^{R}\left(R^{l}\right)$ then yields:

$$
\begin{aligned}
\left(\frac{r_{M}}{r_{M}-r_{F}}\right)\left(\frac{R^{l}-1-r_{F}}{R^{l}}\right) & =\frac{s-\frac{r_{M}\left(R^{l}-\tilde{r}\right)}{R^{l}-r_{M}}}{\tilde{r}-\frac{r_{M}\left(R^{l}-\tilde{r}\right)}{R^{l}-r_{M}}} \\
\left(\frac{r_{M}}{r_{M}-r_{F}}\right)\left(R^{l}-1-r_{F}\right) & =\frac{s\left(R^{l}-r_{M}\right)-r_{M}\left(R^{l}-\tilde{r}\right)}{\tilde{r}-r_{M}}
\end{aligned}
$$

where we have used the definition $s:=\left(q_{F}-\tilde{r}\right) \frac{1-\eta}{\eta} \frac{S\left(q_{F}\right)}{e}$ and $r_{F}:=q_{F}-1$. This equation is linear in $R^{l}$. Solving for $R^{l}$ yields:

$$
\hat{R}^{l}:=r_{M}\left(1+\frac{r_{M}-\tilde{r}}{r_{M}\left(r_{F}-\tilde{r}\right)+s\left(r_{M}-r_{F}\right)}\right)
$$

Inserting this expression for $\hat{R}^{l}$ into (15) yields the equity level:

$$
E^{R}\left(\hat{R}^{l}\right)=\frac{s\left(r_{M}-r_{F}\right)+r_{M}\left(1+r_{F}-\tilde{r}\right)-s}{s\left(r_{M}-r_{F}\right)+r_{M}\left(1+r_{F}-\tilde{r}\right)-\tilde{r}}\left(\frac{e \eta}{n}\right)
$$

It remains to be examined whether $E^{*}\left(R^{l}\right)$ and $E^{R}\left(R^{l}\right)$ are equal for $R^{l} \in\left[q_{F} ; q_{M}\right]$. Note that $E^{R}\left(R^{l}=q_{F}\right)=0$ and $E^{R}\left(R^{l}=q_{M}\right)=\frac{e \eta}{n} \frac{r_{M}}{1+r_{M}}$. From assumption 4 we obtain that $E^{*}\left(R^{l}=q_{F}\right)>0 . E^{*}\left(R^{l}=q_{M}\right)$ is given by:

$$
E^{*}\left(R^{l}=q_{M}\right)=\frac{e \eta}{n} \frac{s-r_{M}\left(q_{M}-\tilde{r}\right)}{q_{M}\left(\tilde{r}-r_{M}\right)}
$$


The following condition guarantees that $E^{*}\left(R^{l}=q_{M}\right)<E^{R}\left(R^{l}=q_{M}\right)$ :

$$
\frac{s-r_{M}\left(q_{M}-\tilde{r}\right)}{\tilde{r}-r_{M}}<r_{M}
$$

By multiplying with $\left(\tilde{r}-r_{M}\right)^{2}$ and rearranging this can be shown to be equivalent to:

$$
\left(s-r_{M}\right)\left(\tilde{r}-r_{M}\right)<0
$$

To proceed, we introduce the following assumption which we assume to hold throughout the paper:

\section{Assumption 5}

$\left(s-r_{M}\right)\left(\tilde{r}-r_{M}\right)<0$

If assumption 5 holds, we have a unique solution for $R^{l} \in\left[q_{F}, q_{M}\right]$ which equalizes $E^{*}\left(R^{l}\right)$ and $E^{R}\left(R^{l}\right)$. After these preparations, we obtain:

\section{Proposition 7}

If assumptions 1 to 5 hold and $\beta=0$, a unique regulatory equity level $\hat{E}^{R}$ exists such that banks just do not gamble and an associated unique subgame-perfect equilibrium.

Proposition 7 shows that the regulator can stipulate an equity level that banks just renounce gambling. However, since the solution $R^{l}$ is in the interval $\left[q_{F}, q_{M}\right]$ and $E^{*}\left(R^{l}=q_{F}\right) \neq E^{R}\left(R^{l}=q_{F}\right), R^{l}$ will exceed $q_{F}$ and thus the moral hazard problem becomes more pronounced at the firm level. The intuition and the consequences of proposition 7 are straightforward. In order to attract the required equity, banks must be able to offer returns as high as $R^{e f}$ which requires larger profit margins $R^{l}-q_{F}$. As a consequence, since $l^{*}$ monotonically decreases in $R^{l}$, loan sizes shrink and thus the moral hazard problem is more pronounced in the sense that aggregate investment in the most profitable (moral hazard) technology declines.

\subsection{Optimal Capital Structure with $\beta \geq 0$}

Finally, we generalize our results for $\beta \neq 0$. In this case, however, explicit solutions are very tedious to obtain. Nevertheless, the main result holds and in the appendix we show: 


\section{Proposition 8}

If assumptions 1 to 5 hold and $\beta \geq 0$, a unique second-best regulatory equity level $\hat{E}^{R}$ exists such that banks just do not gamble.

\section{$5.3 \quad$ Output}

Under regulatory intervention $\hat{E}^{R}$, we calculate aggregate output again assuming $\beta=0$. Aggregate output can be determined as the sum of gross returns for consumers $(1-\eta) S\left(q_{F}\right) q_{F}$ and entrepreneurs. The latter is composed of entrepreneurs' project $\left(\eta q_{M} e^{-}\right)$and returns on bank equity $\left(\eta R^{e b} e^{+}\right)$. Using

$$
\begin{aligned}
R^{e b} & =R^{e f}=\frac{\hat{R}^{l}}{\hat{R}^{l}-r_{M}}=1+\frac{r_{M}\left(r_{F}-\tilde{r}\right)+s\left(r_{M}-r_{F}\right)}{r_{M}-\tilde{r}} \\
e^{+} & =\frac{n}{\eta} E^{R}\left(\hat{R}^{l}\right)=\frac{s\left(r_{M}-r_{F}\right)+r_{M}\left(1+r_{F}-\tilde{r}\right)-s}{s\left(r_{M}-r_{F}\right)+r_{M}\left(1+r_{F}-\tilde{r}\right)-\tilde{r}} e \\
e^{-} & =e-e^{+}=\frac{s-\tilde{r}}{s\left(r_{M}-r_{F}\right)+r_{M}\left(1+r_{F}-\tilde{r}\right)-\tilde{r}} e
\end{aligned}
$$

we obtain the second-best aggregate output

$$
\begin{aligned}
Y^{S B} & =(1-\eta) S\left(q_{F}\right) q_{F}+\eta q_{M}\left(e-\frac{n}{\eta} E^{R}\left(\hat{R}^{l}\right)\right)+\eta R^{e b} \frac{n}{\eta} E^{R}\left(\hat{R}^{l}\right) \\
& =\eta e\left(\frac{1-\eta}{\eta} \frac{S}{e} q_{F}+q_{M}+\frac{n}{\eta e} E^{R}\left(\hat{R}^{l}\right)\left(R^{e f}-q_{M}\right)\right)
\end{aligned}
$$

It is intuitive that $Y^{S B}$ is indeed the second-best aggregate output. If capital requirements were only slightly lower than $\hat{E}^{R}$, banks would gamble completely which lowers aggregate output. This discontinuity in bank investment behavior indicates that $Y^{S B}$ also jumps down when capital requirements are lower than $\hat{E}^{R}$. If capital requirements were higher than $\hat{E}^{R}$, aggregate investment in the profitable moral hazard would decline which lowers aggregate output as well. ${ }^{12}$

The second-best output depends on parameters and allows for interesting comparative statics. For instance, inspecting equation (17) yields:

\section{Corollary 2}

The second-best output is monotonically increasing in the share of entrepreneurs, i.e., $\frac{\partial Y^{S B}}{\partial \eta}>0$

The intuition for corollary 2 is straightforward. A higher share of entrepreneurs

12 The intuitive statement can be proved rigorously by tedious comparisons which we omit. The proof is available from the author. 
alleviates the scarcity of equity, thereby reducing returns on equity. This allows for larger loans per entrepreneur. Aggregate investment in the best technology increases as a result of higher loans and a larger fraction of entrepreneurs.

\section{An Example}

Due to the complexity of assumption 5, we here illustrate the determination of $\hat{R}^{l}$, $E^{R}\left(\hat{R}^{l}\right)$ and $Y^{S B}$ with an example.

$$
\begin{aligned}
& \beta=0 \quad S=2 \quad q_{F}=1 \quad q_{M}=\frac{7}{5} \\
& q_{G}=\frac{8}{5} \quad \quad \quad \quad=2 \quad \eta=\frac{1}{2}
\end{aligned}
$$

Note that $s=\frac{1}{5}$. It is easy to verify that all assumptions are fulfilled and proposition 7 holds. Evaluating the corresponding expressions yields:

$$
\begin{aligned}
& \tilde{r}=\frac{4}{5} \quad \hat{R}^{l}=\frac{16}{15} \quad R^{e b}=R^{e f}=\frac{8}{5} \\
& E^{R}\left(\hat{R}^{l}\right)=\frac{1}{16} \frac{1}{n} \quad Y^{S B}=\frac{193}{80} \quad Y^{F B}=\frac{14}{5}
\end{aligned}
$$

The example illustrates that cost of bank capital can get very high and exceeds the marginal return on the investment projects of entrepreneurs $\left(q_{M}\right)$ by a substantial margin. 


\section{Conclusion}

Our paper has highlighted the fact that an optimal capital structure in an economy must balance multiple incentive problems and that bank capital requirements must be confronted with the need of firms to borrow at an equity level in line with their debt capacity. Our analysis can only be a first step towards a thorough understanding of capital structures for economies. Numerous issues deserve further scrutiny. At a highest level of analysis two issues await more definite answers. First, all considerations of optimal capital structures for economies rely on the plausibility of the assumption about which incentive problems are most important at the bank and at the firm level. Second, how important is bank capital in buffering macroeconomic shocks? ${ }^{13}$ The necessary macroeconomic perspective on these issues promise to generate more guidelines for whether bank capital should be made sensitive to credit risk as it is envisioned in Basel II. ${ }^{14}$

13 Although Gersbach and Wenzelburger (2000) provide a clear-cut answer, this old question is far from being settled.

14 Gersbach and Wehrspohn (2001) e.g. argue that risk sensitivity in Basel II should be captured by the default probability and default correlation only as long as credit risk portfolio models are not used for regulatory purposes. 


\section{Appendix}

\section{Proof of Proposition 2:}

First of all note that no bank would offer a loan contract with $R_{i}^{l}<q_{F}$ since it could always do better by investing in FT. Therefore we can assume that $R_{i}^{l} \geq q_{F}$ for all banks. Second, no bank would offer a loan contract $\left(l_{i}, R_{i}^{l}\right)$ with $l_{i}>l^{*}\left(R_{i}^{l}, e^{-}\right)$or a loan contract with $l_{i}<M-e^{-}$since the firm would never invest in these cases and the bank would receive a lower return than by investing in FT. Statement (i) is a direct consequence of these two observations.

Now suppose that $l^{*}\left(e^{-}\right)+e^{-} \geq M$ and that in a symmetric equilibrium all banks have offered loan contracts $\left(l_{i}, R_{i}^{l}\right)$ with $R_{i}^{l}>q_{F}$. We know by now that $l_{i} \leq$ $l^{*}\left(R_{i}^{l}, e^{-}\right)$. Consider first the case where $e^{-}+l_{i} \geq M$. In this case, bank loans amount to $\eta l_{i}$ and each bank grants $1 / n$ of this amount. But this implies that banks have an incentive to deviate to a contract $\left(\tilde{l}_{i}, \tilde{R}_{i}^{l}\right)$ with $\tilde{R}_{i}^{l}$ slightly lower than $R_{i}^{l}$ and with $\tilde{l}_{i}=l^{*}\left(\tilde{R}_{i}^{l}, e^{-}\right)$. If this contract is offered to the fraction $\tau$ of those entrepreneurs with $\tau \eta \tilde{l}_{i}=F+\eta l_{i} / n$ where $F$ is the amount invested in FT, all entrepreneurs will apply for loans. ${ }^{15}$

This implies that returns on $F$ are now given by $\tilde{R}_{i}^{l}$ instead of $q_{F}$. This compensates for slightly lower returns on $\eta l_{i} / n$ if $\left(R_{i}^{l}-\tilde{R}_{i}^{l}\right)$ is sufficiently small. In the second case, where $e^{-}+l_{i}<M$, no loans are granted and by the same logic as above and the tie-breaking rule, deviation to a contract $\left(\tilde{l}_{i}, \tilde{R}_{i}^{l}\right)$ with $\tilde{R}_{i}^{l}=q_{F}$ and $\tilde{l}_{i}=l^{*}\left(e^{-}\right)$is profitable.

Thus, we have shown that in any equilibrium $R_{i}^{l}=q_{F}$. We therefore know that $l_{i} \leq l^{*}\left(e^{-}\right)$. By our tie-breaking rule, $l_{i}$ cannot be lower than $l^{*}$, since in this case a bank would have an incentive to reallocate resources from FT to loans by offering a contract with $l_{i}=l^{*}\left(e^{-}\right)$. Finally, by the same reasoning as above, deviations from equilibrium (ii) are not profitable. (q.e.d.)

15 This fact can be derived by the following reasoning: As long as $R_{i}^{l} \leq q_{M}$, returns for entrepreneurs are increasing in the offered loan size and decreasing in the loan rate. But $l^{*}\left(\cdot, e^{-}\right)$ is decreasing in $R_{i}^{l}$ and hence $\tilde{R}_{i}^{l}<R_{i}^{l}$ and $\tilde{l}_{i}>l_{i}$. 


\section{Proof of Proposition 5:}

We define $\theta=\frac{D-L}{2 R^{e f}-q_{G}}$, which is positive by assumption.

Moreover, let $\gamma=q_{F}\left(1-\frac{q_{F}}{q_{G}}\right)>0$.

Then

$$
E^{* G}=\left(q_{G}-q_{F}-R^{e f}+\sqrt{R^{e f}\left(R^{e f}-2 \gamma\right)}\right) \theta
$$

We first examine

$$
\frac{\partial E^{* G}}{\partial R^{e f}}=\left(\frac{R^{e f}-\gamma}{\sqrt{R^{e f}\left(R^{e f}-2 \gamma\right)}}-1\right) \theta
$$

$\frac{\partial E^{* G}}{\partial R^{e f}}>0$ if and only if

$$
\left(R^{e f}-\gamma\right)^{2}>R^{e f}\left(R^{e f}-2 \gamma\right)
$$

which is true since $\gamma^{2}>0$. Since $E^{* G}$ is monotonically increasing in $R^{e f}$ and $R^{e f}>q_{F}$, it is sufficient to show that $E^{* G}\left(q_{F}\right)>0$. Setting $R^{e f}=q_{F}$ we obtain

$$
\begin{aligned}
E^{* G}\left(q_{F}\right) & =q_{G}-2 q_{F}+\sqrt{q_{F}\left(q_{F}-2 q_{F}\left(1-\frac{q_{F}}{q_{G}}\right)\right)} \\
& =q_{G}\left(1-\frac{q_{F}}{q_{G}}\left(2-\sqrt{2 \frac{q_{F}}{q_{G}}-1}\right)\right)
\end{aligned}
$$

Setting $\alpha=\frac{q_{F}}{q_{G}}, E^{* G}\left(q_{F}\right)>0$ is equivalent to:

$$
\begin{array}{r}
1-2 \alpha+\alpha \sqrt{2 \alpha-1}>0 \\
\Leftrightarrow \quad \sqrt{2 \alpha-1}(-\sqrt{2 \alpha-1}+\alpha)>0
\end{array}
$$

It remains to be shown that $-\sqrt{2 \alpha-1}+\alpha>0$, which is equivalent to $\alpha^{2}-2 \alpha+1>0$ or $(\alpha-1)^{2}>0$, which always holds for $\alpha \neq 1$, i.e. $q_{F} \neq q_{G}$. Therefore $E^{* G}>0$. (q.e.d.) 


\section{Proof of Proposition 8}

Equation (16) can be written as:

$$
E^{*}\left(R^{l}\right)=a \frac{R^{l}-b}{R^{l}-c}
$$

where we use $J=\frac{1-n}{\eta} \frac{S}{e}$ and the constants $a, b, c$ are given by:

$$
\begin{aligned}
a & =\left(\frac{e \eta}{n}\right)\left(\frac{J\left(q_{F}-\tilde{r}\right)-r_{M}}{\tilde{r}-r_{M}}\right) \\
b & =\frac{J\left(q_{F}-\tilde{r}\right)\left(q_{M}+\beta\right)-\tilde{r} r_{M}}{J\left(q_{F}-\tilde{r}\right)-r_{M}} \\
c & =\frac{\beta \tilde{r}}{\tilde{r}-r_{M}}
\end{aligned}
$$

From assumption 5 it follows that $c<q_{F}$. Since, $a, b, c$ are constants, we observe that

$$
\begin{aligned}
\frac{\partial E^{*}}{\partial R^{l}} & =a \frac{b-c}{\left(R^{l}-c\right)^{2}} \\
\frac{\partial^{2} E^{*}}{\left(\partial R^{l}\right)^{2}} & =\frac{2 a(b-c)}{\left(R^{l}-c\right)^{3}}
\end{aligned}
$$

Hence, $E^{*}\left(R^{l}\right)$ is monotonically increasing or decreasing and either is concave or convex on $\left[q_{F}, q_{M}\right]$. Hence the equation $E^{*}\left(R^{l}\right)=E^{R}\left(R^{l}\right)$ has exactly one solution in $\left[q_{F}, q_{M}\right]$ since $E^{R}\left(R^{l}\right)$ is monotonically increasing and concave and $E^{*}\left(q_{F}\right)>E^{R}\left(q_{F}\right)$ as well as $E^{*}\left(q_{M}\right)<E^{R}\left(q_{M}\right)$. (q.e.d) 


\section{References}

[1] Besanko, D. and G. Kanatas (1993), "Credit Market Equilibrium with Bank Monitoring and Moral Hazard", Review of Financial Studies, 6 (1), 213-232.

[2] Bhattacharya, S., A.W.A. Boot and A.V. Thakor (1998), "The Economics of Bank Regulation", Journal of Money, Credit, and Banking, 30, 4, 745-770.

[3] Blum, J. and M. Hellwig (1995), "The Macroeconomic Implications of Capital Adequacy Requirements", European Economic Review, 39, 733-749.

[4] Bolton, P. and X. Freixas (2000), "Equity, Bonds, and Bank dDebt: Capital Structure and Financial Market Equilibirum under Asymmetric Information", Journal of Political Economy, 108 (2), 324-351.

[5] Boot, A.W.A. and A.V. Thakor (1997), "Financial System Architecture", Review of Financial Studies, 10, 693-733.

[6] Chemmanur, T.J. and P. Fulghieri (1994), "Reputation, Renegotiation, and the Choice between Bank Loans and Publicly Traded Debt", Review of Financial Studies, 7, 475-506.

[7] Covitz, D.M. and E.A. Heitfield(2000), "Monitoring, Moral Hazard, and Market Power: A Model of Bank Lending", Board of Governors of the Federal Reserve System, Washington, DC.

[8] Dewatripont, M. and J. Tirole (1994), "The Prudential Regulation of Banks", MIT Press.

[9] Diamond, D.W. (1984), "Financial Intermediation and Delegated Monitoring", Review of Economic Studies, 51, 447-663

[10] Diamond, D.W. and R. Rajan (2000), "A Theory of Bank Capital" Journal of Finance, 55, 2431-2465.

[11] Gersbach, H. and J. Wenezelburger (2000), "The Consumption Trap" CESifo Working Papier, 7 (1), No. 509.

[12] Gersbach, H. and U. Wehrspohn (2001), "Lean IRB Approaches and Transition Design: Basel II" Working Papier, University of Heidelberg. 
[13] Freixas, X. and J.-C. Rochet (1997), "Microeconomics of Banking", MIT Press, Cambridge, MA.

[14] Gorton, G. and A. Winton (2000), "Liquidity Provision, Bank Capital, and the Macroeconomy", Working Paper.

[15] Holmström, B. and J. Tirole (1997), "Financial Intermediation, Loanable Funds, and the Real Sector", Quarterly Journal of Economics, 112, 663-691.

[16] Hoshi, T., A.K. Kashyap, and D. Scharfstein (1993), "The Choice between Public and Private Debt: An Analysis of Post-deregulation Corporate Financing in Japan", Manuscript. Cambridge: Massachusetts Institute of Technology

[17] Repullo, R. and J. Suarez (2000), "Entrepreneurial Moral Hazard and Bank Monitoring: A Model of the Credit Channel", European Economic Review, 44, 1931-1950. 